Case Report

\title{
Dual Kidney Transplantation after Hypothermic Oxygenated Perfusion from Marginal Donor after Circulatory Death with Acute Kidney Injury: A Case Report
}

Federica Odaldi ${ }^{1}$, Vanessa De Pace ${ }^{1}$, Giacomo Frascaroli ${ }^{1}$, Giuliana Germinario ${ }^{1}$, Giorgia Comai ${ }^{2}$, Francesco Vasuri ${ }^{3}$, Gaetano La Manna ${ }^{2}$, Matteo Ravaioli ${ }^{1, *}$

1. Department of General Surgery and Transplantation, S. Orsola-Malpighi Hospital, University of Bologna, Bologna, Italy; E-Mails: fede.odaldi@gmail.com; vanessa.depace@hotmail.it; giacomo.frascaroli@gmail.com; giulianagerminario96@gmail.com; mrava1@hotmail.com

2. Department of Experimental Diagnostic and Specialty Medicine, Nephrology, Dialysis and Renal Transplant Unit, S. Orsola-Malpighi Hospital, University of Bologna, Bologna, Italy; E-Mails: giorgia.comai@aosp.bo.it; gaetano.lamanna@unibo.it

3. Department of Specialized, Experimental and Diagnostic Medicine, Pathology Unit, S. Orsola Malpighi Hospital, University of Bologna, Bologna, Italy; E-Mail: francesco.vasuri@aosp.bo.it

* Correspondence: Matteo Ravaioli; E-Mails: mrava1@hotmail.com; matteo.ravaioli@aosp.bo.it

Academic Editor: Yasuhiko Sugawara

OBM Transplantation

2020, volume 4, issue 1

doi:10.21926/obm.transplant.2001096
Received: November 22, 2019

Accepted: January 14, 2020

Published: February 03, 2020

\begin{abstract}
Donation after circulatory death (DCD) is an increasingly used resource to alleviate chronic renal graft shortages. Organs from donors with progressively increased creatinine levels due to acute kidney injury are used, but the effects of this condition on kidney transplantation are still unclear. Ex-situ machine perfusion is emerging as a potential tool to preserve and resuscitate vulnerable grafts. We report a case of DCD kidneys discarded due to severe acute kidney injury with favorable histological Karpinski score and transplanted after in-situ normothermic regional perfusion (NRP) and ex-vivo hypothermic oxygenated perfusion (HOPE). Kidneys from a 57-years-old man with circulatory death were discarded by other Italian transplant centers due to high serum creatinine level $(3.66 \mathrm{mg} / \mathrm{dL})$ at the beginning of
\end{abstract}

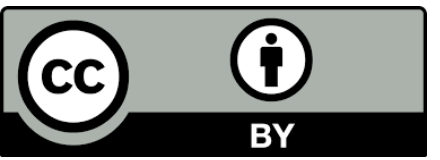

(C2020 by the author. This is an open access article distributed under the conditions of the Creative Commons by Attribution License, which permits unrestricted use, distribution, and reproduction in any mediumor format, provided the original work is correctly cited. 
NRP and for high values during perfusion. The histological Karpinski score was 2 for both kidneys. We performed in-situ NRP for six hours and subsequently HOPE (240 min for the right kidney and 315 min for the left one). Both kidneys showed good median renal flow and low perfusate's lactate levels and led us to use them for dual kidney transplantation. The transplant was performed without any complication. The recipient was discharged with serum creatinine $1.44 \mathrm{mg} / \mathrm{dL}$. At two years of follow-up, no complications were registered and serum creatinine level was $0.8 \mathrm{mg} / \mathrm{dL}$.

\section{Keywords}

Machine perfusion; marginal donors; graft resuscitation

\section{Background}

The shortage of suitable organs for transplantation has led to an increase in the use of "higher risk grafts" defined as marginal or extended criteria donors (ECD) and donors after circulatory death (DCD). In several countries, these grafts represent an increasing source of kidneys suitable for transplantation [1].

In Italy, the use of donors in asystole has developed only recently, mainly because of legislative reasons related to the requirement of more time for the assessment of cardiac death. In fact, 20 min cardiac arrest demonstrated by continuous electrocardiography recording is the time interval necessary in Italy for diagnosis of death based on cardiopulmonary criteria [2, 3]. This "no-touch" period is longer in comparison to worldwide legislation and may have serious implications for early and late graft function after transplantation due to the inevitable period of warm ischemia sustained after circulatory arrest [4]. However, data indicate up to 40-min warm ischemia time to preserve organ viability, and this encouraged Pavia's group to establish the first program of DCD organ transplants in 2007 [2]. Long-term outcomes of transplants from DCD donors appear comparable with those of transplants from donors with beating hearts[5], moreover, for patients waiting for kidney transplantation, standard criteria DCD kidney transplantation is associated with a survival advantage compared with conventional therapy [6]. Recently, kidneys from DCD donors with progressively increased serum creatinine levels $(\mathrm{s} C r$ ) were used with encouraging outcomes [7-12].

Marginal grafts need histological analyses to quantify viable renal mass and predict the outcome of kidney transplantation. The transplant of two marginal kidneys destined to be differently discarded offers an improved filtration power, is safe and well-tolerated as a single transplant. Accordingly, DKT (dual kidney transplantation) and SKT (single kidney transplantation) show comparable data on renal function retrieval and graft survival [13].

In recent years, an increase in the number of marginal donors has led to a rethinking of the organ preservation method. High-risk donation requires an appropriate evaluation of eligibility and alternative storage methods to prevent injury during preservation, restore graft viability, and improve post-transplant function [14]. In DCD, ischemic injury after transplantation can be potentially minimized by restoring circulation with oxygenated blood to the abdominal organs insitu, through extracorporeal membrane oxygenation (ECMO), or normothermic regional perfusion 
(NRP) [15]. Ex-situ machine perfusion is an emerging potential tool to preserve and resuscitate vulnerable grafts, and reduce the discard of organs [16]. Further, hypothermic machine perfusion (HMP) has been shown to improve graft survival and reduce delayed graft function [17-21]. Oxygen delivery during hypothermic preservation (HOPE), also called hypothermic oxygenated perfusion prevents hypoxic injury [22] by increasing adenosine triphosphate content [23]. Although results obtained from preclinical studies are promising [24-26], only a few clinical trials have evaluated oxygenation during HMP in kidney transplantation [27-29] and some trials are ongoing [30]. The development of modern organ preservation techniques have enabled to overcome the restrictions imposed by law related to the prolonged warm ischemia time; the Italian practice for DCD involves starting the regional normothermic perfusion immediately after death declaration, followed by ex-vivo machine perfusion (hypothermic or normothermic) [2, 3, $31]$. In the last three years, there has been a significant expansion in the use of this type of donor [32].

Herein, we used HOPE to recover two DCD kidneys that were declined for use due to donor high sCr level and sCr rise after NRP. We used these kidneys for DKT with a good outcome.

\section{Case Presentation}

\subsection{Donor and Recipient Data}

The DCD donor was a 57-years-old man who developed anoxic encephalopathy after a cardiogenic shock. Risk factors were obesity and dyslipidemia. The donor developed oligo-anuric acute renal injury and the serum creatinine before the cardiac arrest was $3.66 \mathrm{mg} / \mathrm{dL}$ (Table 1).

Table 1 Donor features.

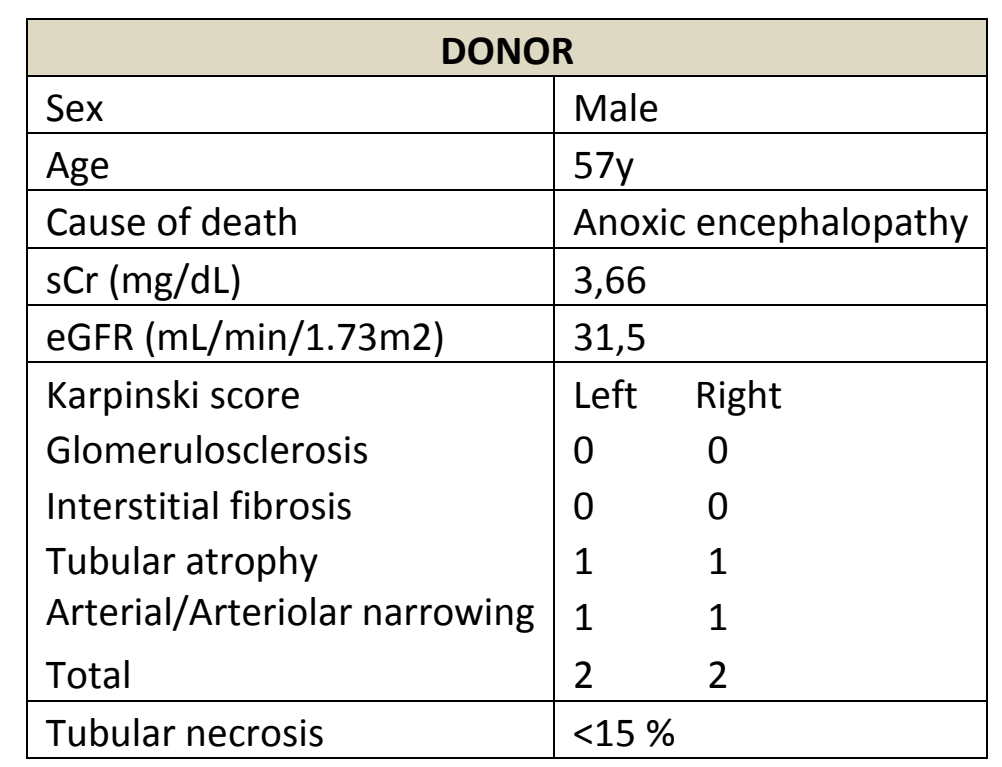

We performed NRP to allow a period of organ assessment and biochemical evaluation of the organ function. The total warm ischemia was $54 \mathrm{~min}$, after which, the NRP was started and performed for six hours. During NRP the laboratory values showed an increase in serum creatinine (from $3.66 \mathrm{mg} / \mathrm{dL}$ to $4.35 \mathrm{mg} / \mathrm{dL}$ ) and the hemogas-analysis showed a decrease in lactate value (from $17 \mathrm{mEq} / \mathrm{lt}$ to $9 \mathrm{mEq} / \mathrm{lt}$ ) and an increase in $\mathrm{pH}$ (from 6.78 to 7.48). A biopsy was performed 
and the histological analysis reported a Karpinski score of 2 for both kidneys (37, Table 1). Other transplant centers declined the kidneys due to the acute injury as well as increased sCr level during NRP. We decided to recover the grafts and preserve them by means of HOPE.

The recipient selected for the DKT was a 75-years-old male patient with chronic renal insufficiency due to autosomal dominant polycystic kidney and liver disease in peritoneal dialysis. The $\mathrm{s} C \mathrm{r}$ value before transplant was $12.9 \mathrm{mg} / \mathrm{dLand}$ the only comorbidity was hypertension (Table 2).

Table 2 Demographical and clinical data of the recipient.

\begin{tabular}{|l|l|}
\hline \multicolumn{2}{|c|}{ RECIPIENT } \\
\hline Age & 75 \\
\hline Sex & Male \\
\hline BMI & 28.2 \\
\hline Blood group & $0-$ \\
\hline IRC Cause & Autosomal dominant polycystic kidney and liver disease \\
\hline sCr before transplant & $12,9 \mathrm{mg} / \mathrm{dL}$ \\
\hline eGFR $(\mathrm{mL} / \mathrm{min} / 1.73 \mathrm{mC})$ & $3.3 \mathrm{ml} / \mathrm{min}$ \\
\hline
\end{tabular}

Ethics approval was not sought as this report contains a single case report for which patient consent was obtained.

\subsection{Ex-Vivo Hypothermic Oxygenated Perfusion}

During the time of hospital transfer following surgical back-table preparation, kidneys were preserved in static cold storage in Belzer solution. Subsequently, organs were connected to the perfusion machine. HOPE was performed for $240 \mathrm{~min}$ for the right and $315 \mathrm{~min}$ for the left kidney, without any complication. For this, we used $1 \mathrm{~L}$ of Belzer solution at $4{ }^{\circ} \mathrm{C}$. The renal artery pressure was $25 \mathrm{mmHg}$. We continuously monitored flow, pressure and temperature values. The median flow was $139 \mathrm{~mL} / \mathrm{min}$ for the right kidney and $58 \mathrm{~mL} / \mathrm{min}$ for the left kidney. Every 15 min, we performed a hemo-gas analysis of the effluent perfusate to monitor oxygen and carbonic dioxide partial pressure ( $\mathrm{pO} 2$ and $\left.\mathrm{pCO}_{2}\right), \mathrm{pH}$, and lactate production. The oxygen partial pressure was between $600-$ and $750-\mathrm{mmHg}$. Carbon dioxide production was not evaluated because it was removed by the oxygenator. Each kidney had perfusion lactate of $1.4 \mathrm{mmol} / \mathrm{L}$ at T1 (Table 3). Figure 1 presents data prior to and after the treatment.

Based on our previous organ perfusion experience, the low level of lactate following HOPE led us to deem both kidneys as transplantable for DKT [28, 33]. 
Table 3 Perfusion and metabolic parameters of the kidneys.

\begin{tabular}{|l|l|l|}
\hline & Right K & Left K \\
\hline Flow median $(\mathrm{ml} / \mathrm{min})$ & 139 & 58 \\
\hline Pressure $(\mathrm{mmHg})$ & 25 & 25 \\
\hline Resistance $\mathrm{Ru}$ & 0,17 & 0,41 \\
\hline Temperature $\left({ }^{\circ} \mathrm{C}\right)$ & 4 & 5 \\
\hline Time $(\mathrm{min})$ & 240 & 315 \\
\hline pH T0 & 7,32 & 7,32 \\
\hline pCO2 To $(\mathrm{mmHg})$ & $<6$ & $<6$ \\
\hline pO2 T0 $(\mathrm{mmHg})$ & 375 & 206 \\
\hline Lat T0 $(\mathrm{mg} / \mathrm{dL})$ & 5,4 & 3,6 \\
\hline pH T1 & 7,17 & 7,2 \\
\hline pCO2 T1 $(\mathrm{mmHg})$ & $<6$ & $<6$ \\
\hline pO2 T1 $(\mathrm{mmHg})$ & $>760$ & $>760$ \\
\hline Lat T1 $(\mathrm{mg} / \mathrm{dL})$ & 12,6 & 12,6 \\
\hline
\end{tabular}

A)

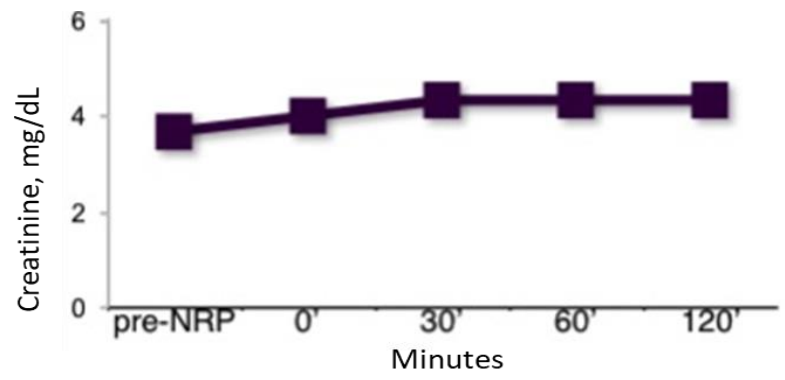

B)

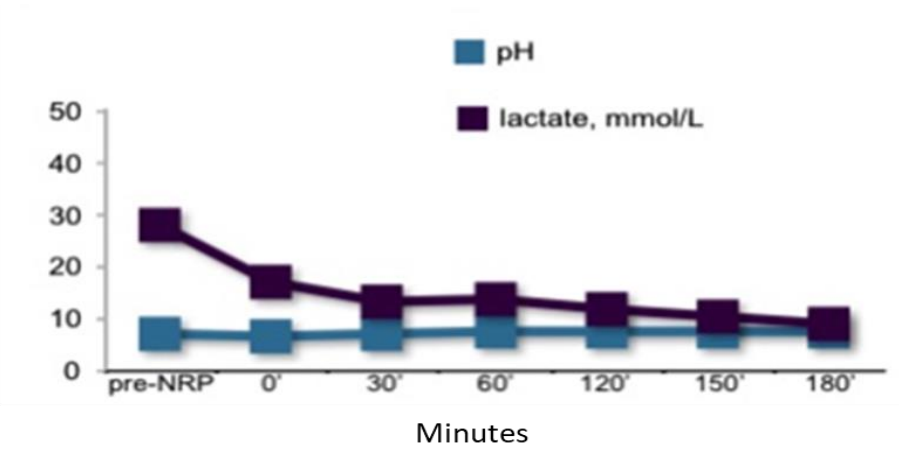

Figure 1 Serum values during NRP. A) Serum creatinine, B) serum lactate and $\mathrm{pH}$.

\subsection{Kidney Transplant and Patient Outcome}

The DKT was performed without any complications. Kidneys were implanted in the right iliac fossa. The vein and artery anastomosis were performed on external iliac vessels. Cold ischemic time was $13 \mathrm{~h}$ for the right kidney and $14 \mathrm{~h}$ for the left kidney. Ureter-to-bladder anastomosis was performed over a single stent. The post-operative immunosuppression therapy was based on thymoglobulin infusion, steroids, and tacrolimus, as per standard protocols [34]. 
The recipient was discharged in 14 days after surgery without any complication. The graft indicated a good function: $4.7 \mathrm{mg} / \mathrm{dLsCr}$ five days after surgery and $3200 \mathrm{~mL} /$ day of diuresis. Serum creatinine level was $1.44 \mathrm{mg} / \mathrm{dL}$ at the time of discharge, $0.83 \mathrm{mg} / \mathrm{dL}$ one month-aftertransplant, and $0.72 \mathrm{mg} / \mathrm{dL}$ six month-after-transplant (Figure 2). At two years of follow-up, no complications were registered and serum creatinine level was $0.8 \mathrm{mg} / \mathrm{dL}$.

$$
\text { eGFR, } \mathrm{ml} / \mathrm{min}-\mathrm{O}-\mathrm{sCr}(\mathrm{mg} / \mathrm{dL})
$$

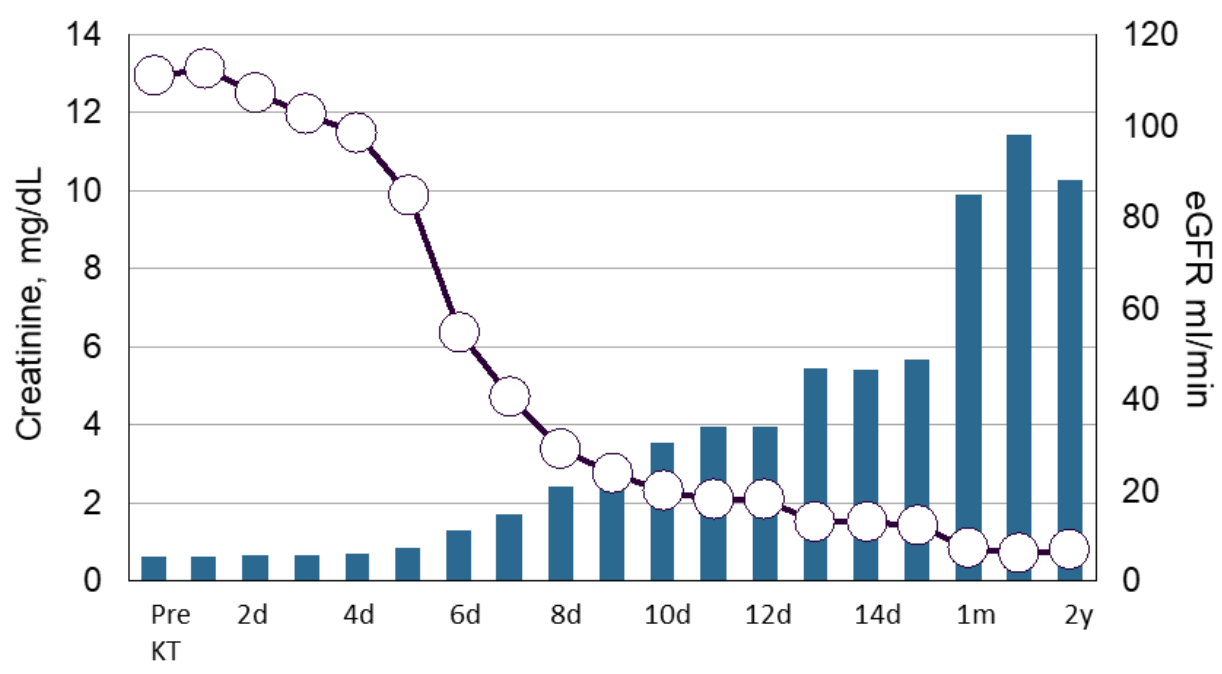

Figure 2 eGFR and serum creatinine levels of the recipient pre and after transplantation. $\mathrm{KT}=$ kidney transplant; $\mathrm{d}=$ days; $\mathrm{m}=$ months; $\mathrm{y}=$ years, eGFR estimated Glomerular Filtration Rate, calculated with Cockcroft- Gault equation.

\section{Discussion and Conclusions}

We report a case of dual kidney transplantation of DCD kidneys. The kidneys were declared untransplantable by other transplant centers because of high serum creatinine levels and increased value during NRP probably due to acute kidney injury during the cardio-circulatory arrest. The histological report showed a Karpinski score of 2 for both kidneys (37) and we decided to perform HOPE to improve the quality of the organs before transplantation. Following HOPE, the level of lactate was low; therefore, we used organs to perform a DKT allowing a greater filtration power, having two marginal organs because the donor was DCD with acute kidney injury (AKI).

The transplant was performed without complication. The renal function and the $\mathrm{sCr}$ were within limits one-month and after two years post-transplantation.

In recent years, because of the shortage of kidneys for transplantation, there has been greater interest in the use of DCD. Several studies have shown that although the use of DCD kidneys is associated with the high-risk incidence of delayed graft function, and transplant outcome, at least in the short term, these indicators are broadly comparable to that of kidneys from donation following brain death [35]. In Italy, there is an issue of the prolonged "no-touch" period with the consequential damages related to the time of ischemia. In this setting, HOPE has a pivotal role in 
reconditioning a marginal graft; moreover, the evaluation of perfusion parameters like flow and pressure is fundamental to defining the suitability of the organ for transplantation.

The prospect of transplanting both kidneys from a high-risk donor, DKT, is a successful approach for optimizing the donor kidney pool [36]. The selection of kidneys for transplantation (SKT or DKT) includes donor data like age, donor history, renal function, macroscopic aspect and histological findings in kidney biopsy [1, 13, 36-39].

Acute kidney injury (AKI) in a previously healthy person, AKI can usually be attributed to a rapid deterioration of the kidney function because of hypoxia, ischemia, or a nephrotoxic agent. Frequently, AKI patients recover spontaneously with the regeneration of damaged tubules [40]. In a recent Japanese study [41] renal grafts from DCD donors with high levels of terminal Cr showed good long-term graft survival, indicating that acute ischemic injury is reversible, even in transplanted kidneys.

The histology score is an important determinant of organ discard but not the only parameter to be considered for SKT or DKT assignment. Some authors added that, besides the histological score, the machine perfusion parameters are also important determinants in deciding to discard an organ [42]. Kayler et al. [43] found that despite a lack of stabilization of the $\mathrm{sCr}$, kidneys with a urine output $\geq 30 \mathrm{cc} / \mathrm{h}$, or with favorable machine perfusion characteristics (flows greater than 100 $\mathrm{mL} / \mathrm{min}$ ) and an absence of chronic changes observed through biopsy, performed just as well as kidneys from donors with stabilized creatinine in terms of primary non-function, exhibited delayed graft function and one-year renal allograft survival.

In this case, we used kidneys from a marginal donor with $\mathrm{s} C r$ values beyond that reported in the literature [7-12, 41, 43]. HOPE allowed us to use these marginal kidneys that showed good histological findings but were discarded due to the acute renal injury. In the reported case, the information gained during perfusion was useful in the selection process. The choice to use both organs to perform DKT was helpful in improving renal function and avoiding graft dysfunction.

We had a previous experience of normothermic perfusion and ex-vivo HOPE for DCD kidneys with good result [44], but to the best of our knowledge, this is the first case to be reported in Italy of AKI in DCD kidney with prolonged warm ischemic time due to 20 min'no-touch' period (as per the Italian law), and with a worse creatinine level during NRP, but which was successfully transplanted with after ex-vivo HOPE.

\section{List of Abbreviations}

ECD: Extended Criteria Donor;DCD: Donation after Circulatory Death Donor; sCr: Serum Creatinine; DKT: Dual Kidney Transplantation; SKT: Single Kidney Transplantation; ECMO: ExtraCorporeal Membrane Oxygenation; NRP:Normothermic Regional Perfusion; HMP: Hypothermic Machine Perfusion; HOPE: Hypothermic Oxygenated Perfusion; DGF: Delayed Graft Function; DBD: Donation after Brain Death; AKI: Acute Kidney Injury

\section{Consent for Publication}

Written informed consent was given by the patient to publish the information in this case report. Written informed consent was given by the next of kin of the deceased person to publish the information in this case report. 


\section{Availability of Data and Materials}

Data sharing is not applicable to this article as no datasets were generated or analyzed during the current study.

\section{Author Contributions}

FO: study design, article drafting, VDP and GG: clinical activity and revision of the article, GF: surgical activity and revision of the article, GC: clinical activity and revision of the article, FV: histopathological diagnosis and revision of the article, GLM: clinical activity and revision of the article, MR: surgical activity and revision of the article. All authors reviewed and approved the final version of the manuscript.

\section{Competing Interests}

The authors have declared that no competing interests exist.

\section{References}

1. Pascual J, Zamora J, Pirsch JD. A systematic review of kidney transplantation from expanded criteria donors.Am J Kidney Dis. 2008; 52:553-586.

2. Geraci PM, Sepe V. Non-heart-beating organ donation in Italy. Minerva Anestesiol.2011; 77:613-623.

3. Busutti $M$, Minerva V, Angeletti A, Corradetti V, Zanfi C, Ravaioli M, et al. Kidney transplant from donors after cardiac death (DCD): Monocentric experience and literature review. G ItalNefrol. 2019;36: pii: 2019-vol4.

4. Van Heurn LWE, Talbot D, Nicholson ML, Akhtar MZ, Sanchez-Fructuoso Al, Weekers L, et al. Recommendations for donation after circulatory death kidney transplantation in Europe. Transpl Int. 2016; 29: 780-789.

5. Kokkinos C, Antcliffe D, Nanidis T, Darzi AW, Tekkis P, Papalois V. Outcome of kidney transplantation from nonheart-beating versus heart-beating cadaveric donors. Transplantation.2007; 83:1193-1199.

6. Snoeijs MG, Schaubel DE, Hene R, Hoitsma AJ, Idu MM, ljzermans JN, et al. Kidneys from donors after cardiac death provide survival benefit. J Am SocNephrol. 2010; 21:1015-1021.

7. Anil Kumar MS, Khan SM, Jaglan S, Heifets M, Moritz MJ, Saeed MI, et al. Successful transplantation of kidneys from deceased donors with acute renal failure: Three years results. Transplantation.2006; 82:1640-1645.

8. Morgan C, Martin A, Shapiro R, Randhawa PS, Kayler LK. Outcomes after transplantation of deceased-donor kidneys with rising serum creatinine. Am J Transplant.2007; 7:1288-1292.

9. Nagaraja P, Roberts GW, Stephens M, Horvath S, Kaposztas Z, Chavez R, et al. Impact of expanded criteria variables on outcomes of kidney transplantation from donors after cardiac death. Transplantation.2015; 99:226-231.

10. Chavalitdhamrong D, Gil J, Takemoto S, Madhira BR, Cho YW, Shah T, et al. Patient and graft outcomes from deceased kidney donors age 70 years and older: an analysis of the Organ 
Procurement Transplant Network/United Network of Organ Sharing database. Transplantation.2008; 85:1573-1579.

11. Heilman RL, Smith ML Kurian SM, Huskey J, Batra RK, Chakkera HA, et al. Transplanting kidneys from deceased donors with severe acute kidney injury. Am J Transplant.2015; 15:2143-2151.

12. Farney AC, Rogers J, Orlando G, al-Geizawi S, Buckley M, Farooq U, et al. Evolving experience using kidneys from deceased donors with terminal acute injury. J Am Coll Surg. 2013; 216:645655.

13. Remuzzi G, Grinyo J, Ruggenenti P, Beatini M, Cole EH, Milford EL, et al. Early experience with dual kidney transplantation in adults using expanded donor criteria. J Am SocNephrol. 1999; 10:2591-2598.

14. Hameed AM, Hawthorne WJ, Pleass HC. Advances in organ preservation for transplantation.ANZ J Surg. 2017; 87:976-980.

15. Oniscu GC, Randle LV, Muiesan P, Butler AJ, Currie IS, Perera MT, et al. In situ normothermic regional perfusion for controlled donation after circulatory death--the United Kingdom experience.Am J Transplant.2014; 14:2846-2854.

16. Fondevila C, Hessheimer AJ, Ruiz A, Calatayud D, Ferrer J, Charco R, et al. Liver transplant using donors after unexpected cardiac death: Novel preservation protocol and acceptance criteria. Am J Transplant.2007; 7:1849-1855.

17. Jochmans I, Akhtar MZ, Nasralla D, Kocabayoglu P, Boffa C, Kaisar M,et al. Past, present and future of dynamic kidney and liver preservation and resuscitation. Am J Transplant.2016; 16: 2545-2555.

18. Matsuno N, Sakurai E, Tamaki I, Uchiyama M, Kozaki K, Kozaki M. The effect of machine perfusion preservation versus cold storage on the function of kidneys from non-heart-beating donors.Transplantation.1994; 57:293-294.

19. O'Callaghan JM, Morgan RD, Knight SR, Morris PJ. Systematic review and meta-analysis of hypothermic machine perfusion versus static cold storage of kidney allografts on transplantation outcomes.Br J Surg. 2013; 100:991-1001.

20. Tolstykh GP, Gelineau JF, Maier LM, Bunegin L. Novel portable hypothermic pulsatile perfusion preservation technology: Improved viability and function of rodent and canine kidneys. Ann Transplant. 2010; 15:35-43.

21. Kwiatkowski A, Wszoła M, Kosieradzki M, Danielewicz R, Ostrowski K, Domagala $P$, et al. The early and long term function and survival of kidney allografts stored before transplantation by hypothermic pulsatile perfusion. A prospective randomized study. Ann Transplant. 2009; 14:14-17.

22. Thuillier R, Allain G, Celhay O, Hebrard W, Barrou B, Badet L, et al. Benefits of active oxygenation during hypothermic machine perfusion of kidneys in a preclinical model of deceased after cardiac death donors. J Surg Res. 2013; 184:1174-1181.

23. Hosgood SA, Nicholson HF, Nicholson ML. Oxygenation kidney preservation techniques. Transplantation.2012; 93:455-459.

24. Patel K, Smith TB, Neil DAH, Thakker A, Tsuchiya Y, Higgs EB, et al. The effects of oxygenation on ex vivo kidneys undergoing hypothermic machine perfusion.Transplantation. 2019;103:314-322. 
25. Venema LH, Brat A, Moers C, 't Hart NA, Ploeg RJ, Hannaert P, et al. Effects of oxygen during long-term hypothermic machine perfusion in a porcine model of kidney donation after circulatory death. Transplantation.2019; 103:2057-2064.

26. Kasil A, Giraud S, Couturier P, Amiri A, Danion J, Donatini G, et al. Individual and combined impact of oxygen and oxygen transporter supplementation during kidney machine preservation in a porcine preclinical kidney transplantation model. Int J Mol Sci. 2019; 20: pii: E1992.

27. Meister FA, Czigany Z, Bednarsch J, Boecker J, Wiltberger G, Rohlfs W, et al. Hypothermic oxygenated machine perfusion-Preliminary experience with end-ischemic reconditioning of marginal kidney allografts. Clin Transplant. 2019; 33:e13673.

28. Ravaioli M, De Pace V, Comai G, Busutti M, Del Gaudio M, Amaduzzi A, et al. Sussessful dual kidney transplantation after hypotermic oxygenated perfusion of discharged human kidneys. Am J Case Rep. 2017; 18:1009-1013.

29. Ravaioli M, De Pace V, Comai G, Capelli I, Baraldi O, D'Errico A, et al. Preliminary experience of sequential use of normothermic and hypothermic oxygenated perfusion for donation after circulatory death kidney with warm ischemia time over the conventional criteria - a retrospective and observational study. Transpl Int. 2018; 31:1233-1244.

30. Meister FA, Czigany Z, Bednarsch J, Böcker J, Amygdalos I, Morales Santana DA, et al. Hypothermic oxygenated machine perfusion of extended criteria kidney allografts from brain dead donors: Protocol for a prospective pilot study. JMIR Res Protoc. 2019;8: e14622.

31. Olivieri T, Magistri P, Guidetti C, Baroni S, Rinaldi S, Assirati G, et al. University of modenaexperience with liver grafts from donation after circulatory death: What really matters in organ selection? Transplant Proc. 2019;51:2967-2970.

32. Global Observatory on Donation and Transplantation. November 1, 2018.

33. Ravaioli $M$, De Pace $V$, Pinna AD. From six thousand transaminases level to three hundred after liver transplantation: A new era seems to be open. Update Surg. 2017; 69: 549-550.

34. Kidney Disease: Improving Global Outcomes (KDIGO) Transplant Work Group. KDIGO clinical practice guideline for the care of kidney transplant recipients.Am J Tranplant. 2009; 9:S1-S155.

35. Wells AC, Rushworth L, Thiru S, Sharples L, Watson CJ, Bradley JA, et al. Donor kidney disease and transplant outcome for kidneys donated after cardiac death. Br J Surg. 2009; 96: 299-304.

36. Snoeijs MG, Buurman WA, Christiaans MH, van Hooff JP, Goldschmeding R, van Suylen RJ, et al. Histological assessment of preimplantation biopsies may improve selection of kidneys from old donors after cardiac death. Am J Transplant.2008; 8:1844-1851.

37. Karpinski J, Lajoie G, Cattran D, Fenton S, Zaltzman J, Cardella C, et al. Outcome of kidney transplantation from high-risk donors is determined by both structure and function. Transplantation.1999; 67:1162-1167.

38. Port FK, Bragg JL, Metzger RA, Dykstra DM, Gillespie BW, Young EW, et al. Donor characteristics associated with reduced graft survival: An approach to expanding the pool of kidney donors. Transplantation 2002; 74:1281-1286.

39. La Manna G, Comai G, Cappuccelli ML, LivianoD'Arcangelo G, Fabbrizio B, Valentini C, at al. Prediction of three- year outcome of renal transplantation from optimal donors versus expanded criteria donors. Am J Nephrol.2013; 37:158-166. 
40. Thurman JM. Triggers of inflammation after renal ischemia/reperfusion.Clinlmmunol. 2007; 123:7-13.

41. Tomita Y, Tojimbara T, Iwadoh K, Nakajima I, Fuchinoue S. Outcomes of kidney transplantation from circulatory death donors with increased terminal creatinine levels in serum. Transplantation 2016; 100:1532-1540.

42. Sung RS, Christensen LL, Leichtman AB, Greenstein SM, Distant DA, Wynn JJ, et al. Determinants of discard of expanded criteria donor kidneys: impact of biopsy and machine perfusion. Am J Transplant.2008; 8:783-792.

43. Kayler LK, Garzon P, Magliocca J, Fujita S, Kim RD, Hemming AW, et al. Outcomes and utilization of kidneys from deceased donors with acute kidney injury. Am J Transplant.2009; 9:367-373.

44. Ravaioli M, De Pace V, Comai G, Capelli I, Baraldi O, D’Errico A, et al. Preliminary experience of sequential use of normothermic and hypothermic oxygenated perfusion for donation after circulatory death kidney with warm ischemia time over the conventional criteria - A retrospective and observational study. Transpl Int. 2018; 31:1233-1244.

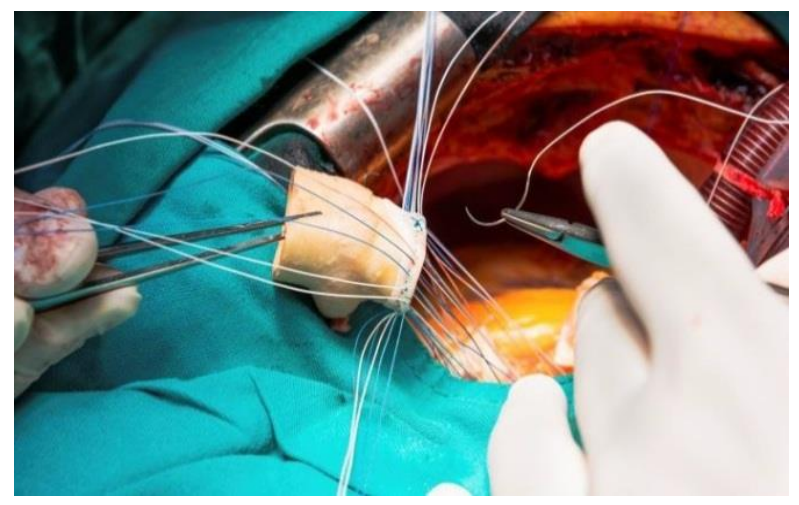

Enjoy OBM Transplantationby:

1. Submitting a manuscript

2. Joining in volunteer reviewer bank

3. Joining Editorial Board

4. Guest editing a special issue

For more details, please visit:

http://www.lidsen.com/journals/transplantation 